\title{
Mode-Matching Analysis of Acoustic Wave Propagation along a Rigid Coaxial Pipe with an Internal Impedance Loading
}

\author{
Hülya Öztürk ${ }^{1 *}$ \\ 1* Gebze Technical University, Department of Mathematics, Kocaeli, Turkey, (ORCID: 0000-0002-7814-718X), h.ozturk@gtu.edu.tr
}

(1st International Conference on Applied Engineering and Natural Sciences ICAENS 2021, November 1-3, 2021)

(DOI: 10.31590/ejosat.1008469)

ATIF/REFERENCE: Öztürk, H. (2021). Mode-Matching Analysis of Acoustic Wave Propagation along a Rigid Coaxial Pipe with an Internal Impedance Loading. European Journal of Science and Technology, (28), 515-518.

\begin{abstract}
Mathematical analysis of the acoustic wave propagation along the coaxial waveguide, whose right part of the outer wall is impedancecoated, is considered. By determining the boundary conditions corresponding to the relevant geometry, the boundary value problem is solved by applying the Mode-Matching technique. At the end of the analysis, numerical computations are carried out to illustrate the affect of some parameters. The results demonstrate the significance of the absorbing lining in reducing the unwanted noise.
\end{abstract}

Keywords: Mode-Matching, Coaxial Waveguide, Acoustics, Absorbent Lining.

\section{Dış Duvarının Yarısı Akustik Yutucu Malzeme ile Kaplı Rijit Koaksiyel Bir Boruda Akustik Dalgaların Yayılımının Mod-Uydurma ile Analizi}

$\ddot{O} \mathbf{z}$

Dış duvarının yarısı akustik yutucu malzeme ile kaplı koaksiyel bir boruda akustik dalgaların yayılımının analizi yapılmıştır. İlgili geometriye karşılık gelen sınır koşulları belirlenmiş ve bu koşullardan faydalanılarak mod uydurma tekniği ile sınır değer problemi çözülmüştür. Analizin sonunda ise, bazı parametrelerin ses yayılımına etkisi nümerik sonuçlar ile sunulmuştur. Akustik yutucu malzeme sayesinde istenmeyen gürültünün azaltılabileceği görülmüştür.

Anahtar Kelimeler: Mod-Uydurma, Koaksiyel Dalga Kılavuzu, Akustik, Yutucu Malzeme.

\footnotetext{
* Corresponding Author: h.ozturk@gtu.edu.tr
} 


\section{Introduction}

The propagation of sound waves along ducts has been the focus of attention by researchers for many years due to its importance in noise reduction. There are a lot of analytical and numerical methods have been studied by many scientists [1-8]. One of the most effective methods is the Mode-Matching or eigenfunction expansion technique, which is based on representing the unknown fields in terms of an infinite sum of orthogonal functions in the individual regions and then matching them across the boundaries between these regions. This method has been applied in many papers [9-13] and give accurate results.

The present work deals with the mode-matching analysis of the coaxial waveguide problem. The critical situation here is that part of the outer wall is loaded with impedance. The aim is to show the effect of partial absorbing surface on sound propagation. For this purpose, the geometry is divided into two region and then the potentials satisfying boundary conditions in each region are established in terms of their normal modes by using seperation of variables. The solution leads to infinite set of linear equations which are solved numerically. Finally, graphs are displayed for different parameters. It is observed that, the absorbing surface. has a significant effect on reducing harmful and undesired noise.

\section{Formulation of the Problem}

Assume an acoustic wave propagating in a coaxial duct shown Figure 1. The material properties of the right part of the outer wall is simulated by a specific admittance of $\eta=\rho_{0} c / Z$ where $\mathrm{c}$ is the velocity of sound and $Z$ is the liner impedance.

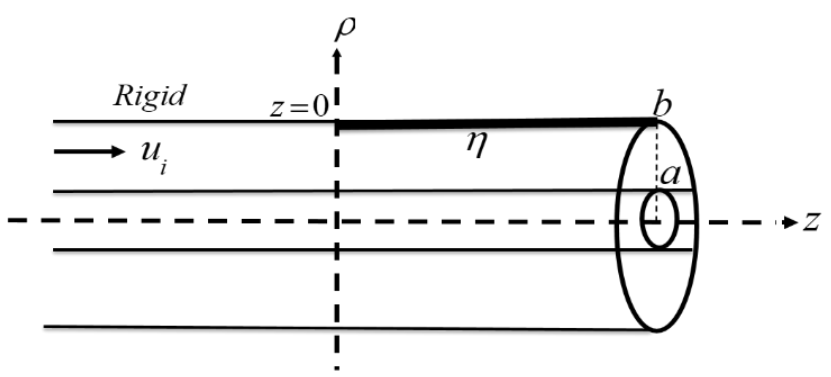

Fig. 1 Geometry of the problem.

Let an incident acoustic wave with time dependence $\exp (-i \omega t)$ where $\omega$ is the angular frequency is given by

$$
u_{i}(z)=e^{i k z}
$$

Here $k=\omega / c$ is the wave number. As it well

known, the total field

$\mathrm{u}_{T}(\rho, z)=\left\{\begin{array}{ccc}u_{1}(\rho, z)+u_{i}(z) & ; a<\rho<b ; & ; \in(-\infty, 0) \\ u_{2}(\rho, z) & ; a<\rho<b ; z \in(0, \infty)\end{array}\right.$

satisfies the Helmholtz equation

$\left[\frac{1}{\rho} \frac{\partial}{\partial \rho}\left(\rho \frac{\partial}{\partial \rho}\right)+\frac{\partial^{2}}{\partial z^{2}}+k^{2}\right] u_{j}(\rho, z)=0, j=1,2$

and the following boundary and continuity conditions:

e-ISSN: 2148-2683 $\frac{\partial}{\partial \rho} u_{T}(a, z)=0, \quad-\infty<z<\infty$

$\frac{\partial}{\partial \rho} u_{1}(\mathrm{~b}, z)=0 \quad, \quad-\infty<z<0$

$\left(i k \eta-\frac{\partial}{\partial \rho}\right) u_{2}(b, z)=0,0<z<\infty$

$\frac{\partial}{\partial z} u_{1}(\rho, 0)+\frac{\partial}{\partial z} u_{i}(0)=\frac{\partial}{\partial z} u_{2}(\rho, 0)$

$u_{1}(\rho, 0)+u_{i}(0)=u_{2}(\rho, 0)$

The functions $u_{j}(\rho, z), j=1,2$ appearing in (3) are the unknown fields.

Solutions of Helmholtz equation (3) obtained by means of separation of variables method, with boundary conditions (4-6) are given by

$u_{1}(\rho, z)=\sum_{n=1}^{\infty} a_{n} e^{-i \alpha_{n} z} \varphi_{n}(\rho)$

$u_{2}(\rho, z)=\sum_{n=1}^{\infty} b_{n} e^{i \chi_{n} z} \psi_{n}(\rho)$

where $a_{n}$ and $b_{n}$ are the magnitudes of the reflected and transmitted duct mode, respectively. The eigenvalues $\alpha_{n}$ and $\chi_{n}$ are the solutions of

$K_{n}\left[J_{1}\left(K_{n} a\right)-\frac{J_{1}\left(K_{n} b\right)}{Y_{1}\left(K_{n} b\right)} Y_{1}\left(K_{n} a\right)\right]=0, n=1,2, \ldots$
$\xi_{n}\left[J_{1}\left(\xi_{n} a\right)-\frac{\left[i k \eta J_{0}\left(\xi_{n} b\right)+\xi_{n} J_{1}\left(\xi_{n} b\right)\right]}{\left[i k \eta Y_{0}\left(\xi_{n} b\right)+\xi_{n} Y_{1}\left(\xi_{n} b\right)\right]} Y_{1}\left(\xi_{n} a\right)\right]=0, n=1,2, \ldots$

with

$$
\begin{aligned}
& \alpha_{n}=\sqrt{k^{2}-K_{n}^{2}}, \quad n=1,2, \ldots \\
& \chi_{n}=\sqrt{k^{2}-\xi_{n}^{2}}, \quad n=1,2, \ldots
\end{aligned}
$$

We define eigenfunctions as

$\varphi_{n}(\rho)=\left[J_{0}\left(K_{n} \rho\right)-\frac{J_{1}\left(K_{n} b\right)}{Y_{1}\left(K_{n} b\right)} Y_{0}\left(K_{n} \rho\right)\right]$

$\psi_{n}(\rho)=\left[J_{0}\left(\xi_{n} \rho\right)-\frac{\left[i k \eta J_{0}\left(\xi_{n} b\right)+\xi_{n} J_{1}\left(\xi_{n} b\right)\right]}{\left[i k \eta Y_{0}\left(\xi_{n} b\right)+\xi_{n} Y_{1}\left(\xi_{n} b\right)\right]} Y_{0}\left(\xi_{n} \rho\right)\right]$

Here $J_{n}$ and $Y_{n} \quad(n=0,1)$ stand for Bessel and Neumann functions.

In order to obtain the solution let us apply continuity conditions (7) and (8): 
$-\sum_{m=1}^{\infty} a_{m} \alpha_{m} \varphi_{m}(\rho)+k=\sum_{n=1}^{\infty} \chi_{n} b_{n} \psi_{n}(\rho)$

$\sum_{m=1}^{\infty} a_{m} \varphi_{m}(\rho)+1=\sum_{n=1}^{\infty} b_{n} \psi_{n}(\rho)$

Considering now the integral of (17) and (18) after multiplying the both sides with $\rho \psi_{n}(\rho)$ and using the following orthogonality relation

$$
\begin{aligned}
& \int_{a}^{b} \psi_{m}(\rho) \psi_{n}(\rho) \rho d \rho= \\
& \frac{4 i k \eta}{\left[i k \eta Y_{0}\left(\xi_{n} \mathrm{~b}\right)+\xi_{n} Y_{1}\left(\xi_{n} \mathrm{~b}\right)\right] \pi^{2} b K_{m} Y_{1}\left(\mathrm{~K}_{m} \mathrm{~b}\right)\left(\mathrm{K}_{m}^{2}-\xi_{n}^{2}\right)}
\end{aligned}
$$

give

$-\frac{2}{\pi b} S\left(b, k, \eta, \xi_{n}\right) \sum_{m=1}^{\infty} \frac{a_{m} \alpha_{m}}{K_{m} Y_{1}\left(\mathrm{~K}_{m} \mathrm{~b}\right)\left(K_{m}^{2}-\xi_{n}^{2}\right)}+\frac{k}{\xi_{n}^{2}} S\left(b, k, \eta, \xi_{n}\right)=\chi_{n} P_{n} b_{n}$

$\frac{2}{\pi b} S\left(b, k, \eta, \xi_{n}\right) \sum_{m=1}^{\infty} \frac{a_{m}}{K_{m} Y_{1}\left(\mathrm{~K}_{m} \mathrm{~b}\right)\left(K_{m}^{2}-\xi_{n}^{2}\right)}+\frac{1}{\xi_{n}^{2}} S\left(b, k, \eta, \xi_{n}\right)=P_{n} b_{n}$

where

$$
S\left(b, k, \eta, \xi_{n}\right)=\frac{2 i k \eta}{\pi\left[i k \eta Y_{0}\left(\xi_{n} \mathrm{~b}\right)+\xi_{n} Y_{1}\left(\xi_{n} \mathrm{~b}\right)\right]}, \quad P_{n}=\int_{a}^{b} \psi_{n}^{2}(\rho) \rho d \rho
$$

As a result, constructing the system of linear equations properly the coefficients $a_{m}$ and $b_{m}$ can be determined numerically

\section{Graphical Results}

This section contains graphs of the transmission loss, written

$$
T L=-20 \log _{10}\left|T_{0}\right|
$$

for varied values of $\eta$, a and $\mathrm{b}$.

Figures 2 and 3 show the modules of the reflection and transmission fields with respect to truncation number for infinite system (N). It can be seen that amplitudes become insensitive for $N>3$. Hence $\mathrm{N}$ is chosen 10 in our computations.



Fig. 2 Reflection field amplitude versus the truncation number $\mathrm{N}$.



Fig. 3 Transmission field amplitude versus the truncation number $\mathrm{N}$.

Figures 4 and 5 show the variation of transmission loss for different values of surface impedance $(\eta)$. It can be easily seen that it is possible to decrease the transmission loss for different values $\eta$.



Fig. 4 Transmission loss for different values of real part of $\eta^{-1}$.



Fig. 5 Transmission loss for different values of imaginary part of $\eta^{-1}$.

Figures 6 and 7 depict the transmission loss variation for different values of duct radii $a$ and $b$. These graphs were obtained when $\eta^{-1}=1-i$. One can see that the when a and $b$ increase, the transmission loss decreases. 


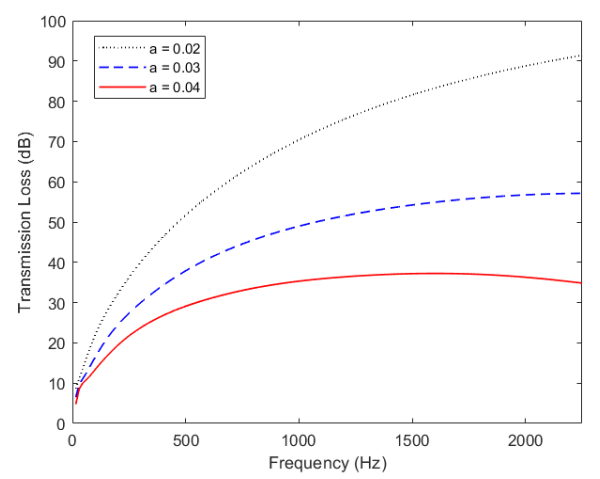

Fig. 6 Transmission loss for different values of duct radius a.

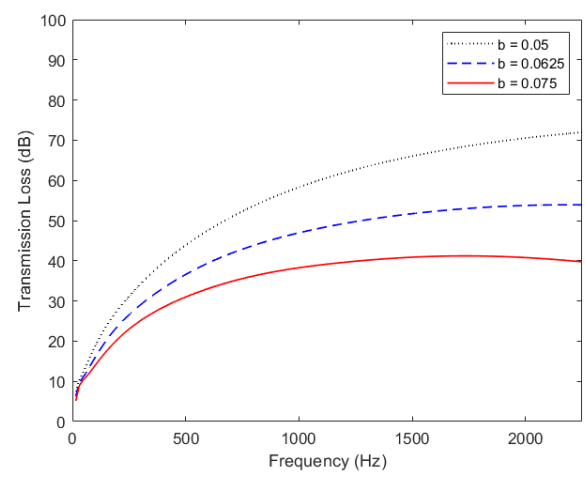

Fig. 7 Transmission loss for different values of duct radius $b$.

Finally, Figure 8 shows the contribution of the lining on noise reduction. As expected, the transmission field decreases with the effect of surface impedance.



Fig. 8 Transmission field for rigid-lined duct.

\section{Conclusion}

In this study, the effect of partial lining to the sound transmission is studied through the Mode-Matching technique. Some numerical results are presented for some particular parameters The results show that it is possible to reduce sound by changing the parameters. In addition, the results are compared with the rigid duct. It is observed that the use of lining provides significant sound absorption.

\section{References}

[1] Rawlins, A. D. "Radiation of sound from an unflanged rigid cylindrical duct with an acoustically absorbing internal surface," Proc. R. Soc. A., vol. 361, pp. 65-91, 1978.

[2] Rienstra, S. W. "Acoustic scattering at a hard-soft lining transition in a flow duct," J. Eng. Math., vol. 59, pp. 451475, 2007.

[3] Lawn, C. "Calculation of acoustic absorption in ducts with perforated liners," Appl. Acoust., vol. 89, pp. 211-221, 2015.

[4] Çınar, G., Öztürk H., and Çınar, Ö. Y. "Reflection and transmission of plane acoustic waves in an infinite annular duct with a finite gap on the inner wall," Math. Methods Appl. Sci., vol. 34, pp. 220-230, 2011.

[5] Levine H., and Schwinger, J. "On the radiation of sound from an unflanged circular pipe," Phys. Rev., vol. 73, pp. 383-406, 1948.

[6] Sobolev, A. F., and Yakovets, M. A. "Application of the Wiener-Hopf method for describing the propagation of sound in cylindrical and rectangular channels with an impedance jump in the presence of a flow," Acoust. Phys., vol. 63, pp. 623-636, 2017.

[7] Peake, N., and Abrahams, I. D. "Sound radiation from a semi-infinite lined duct, "Wave Motion, vol. 92, 102407, 2020.

[8] Öztürk, H. "Radiation of acoustic waves from a circumferential slot on a circular waveguide," TWMS J. of Appl. and Eng. Math., vol. 10, pp. 690-701, 2020.

[9] Hassan, M., Meylan, H. M., Bashir, A., and Sumbul, M. "Radiation matching analysis for wave scattering in triple and pentafurcated spaced ducts," Math. Methods Appl. Sci., vol. 39, pp. 3043-3057, 2016.

[10] Shafique, S., Afzal, M., and Nawaz, R. "On mode-matching analysis of fluid structure coupled wave scattering between two flexible waveguides," Can. J. Phys., vol. 95, pp. 585$589,2017$.

[11] Hassan, M., and Bashir, A. "Effect of soft outer lining in pentafurcated duct," Can. J. Phys., vol. 96, pp. 165-173, 2018.

[12] Kuryliak, D. B., and Sharabura, O. M. "Wave diffraction from the biconical section in the semi-infinite conical region," Math. Methods Appl. Sci., vol. 43, pp. 1565-1581, 2019.

[13] Khalid, A., Younas, S., Khan, I., Manzoor, R., Rab, N., and Sherif, E. M. "Mode-matching analysis for two-dimensional acoustic wave propagation in a trifurcated lined duct," $J$. Interdiscip Math., vol. 22, pp. 1095-1112, 2020. 